\title{
How many electric miles do Nissan Leafs and Chevrolet Volts in The EV Project travel?
}

\author{
John Smart
}

May 2014

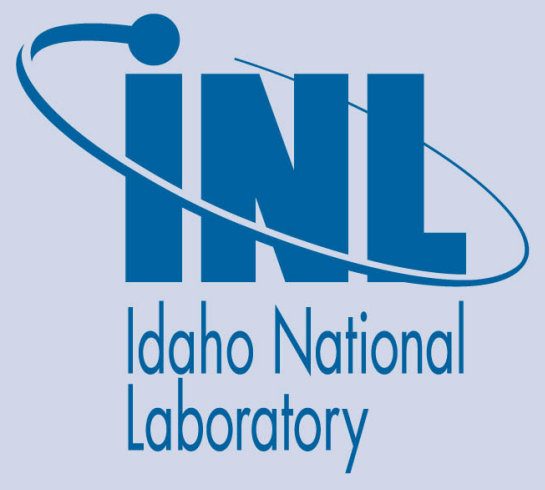

The INL is a U.S. Department of Energy National Laboratory operated by Battelle Energy Alliance 
DISCLAIMER

This information was prepared as an account of work sponsored by an agency of the U.S. Government. Neither the U.S. Government nor any agency thereof, nor any of their employees, makes any warranty, expressed or implied, or assumes any legal liability or responsibility for the accuracy, completeness, or usefulness, of any information, apparatus, product, or process disclosed, or represents that its use would not infringe privately owned rights. References herein to any specific commercial product, process, or service by trade name, trade mark, manufacturer, or otherwise, does not necessarily constitute or imply its endorsement, recommendation, or favoring by the U.S. Government or any agency thereof. The views and opinions of authors expressed herein do not necessarily state or reflect those of the U.S. Government or any agency thereof. 
INL/EXT-14-32135

\section{How many electric miles do Nissan Leafs and Chevrolet Volts in The EV Project travel?}

John Smart

May 2014

Idaho National Laboratory

Idaho Falls, Idaho 83415

http://www.inl.gov

Prepared for the U.S. Department of Energy

Office of Energy Efficiency and Renewable Energy Under DOE Idaho Operations Office Contract DE-AC07-05ID14517 


\section{$=$ V/Project}

\section{How many electric miles do Nissan Leafs and Chevrolet Volts in The EV Project travel?}

May 2014

\section{Key Conclusions}

- Between October 2012 and December 2013, Nissan Leaf drivers in The EV Project averaged 808.1 electric vehicle miles traveled per month. Chevrolet Volt drivers in The EV Project Volt averaged 759.3 electric vehicle miles traveled per month and 1,019.8 total vehicle miles traveled per month.

- The distributions of electric vehicle miles traveled per month for Leafs and Volts overlap significantly, indicating that many Volts drove the same or more electric miles than Leafs, despite a large difference in electric range.

- Change in electric vehicle miles traveled from month to month over the 15 month study period was similar for Leafs and Volts, suggesting that seasonal effects influence drivers of both vehicles in the same way.

\section{Introduction}

Battery electric vehicles, such as the Nissan Leaf, are powered exclusively by electricity. The maximum driving range between refueling - in this case recharging - of a battery electric vehicle is limited by the energy storage capacity of the vehicle's battery. Extended-range electric vehicles, such as the Chevrolet Volt, can also be powered exclusively by electricity; however, they have smaller batteries and, therefore, shorter electric vehicle (EV) mode range than battery electric vehicles. Extended-range electric vehicles provide range extension using an internal combustion engine. The electric ranges of battery electric vehicles and extended-range electric vehicles are quantified by auto manufacturers and third parties such as the U.S. Environmental Protection Agency (EPA). However, it is the owners' driving and charging behavior that determines how much distance is actually traveled using electric power.

This paper investigates the observed monthly distance traveled when powered solely by electricity, or electric vehicle miles traveled (eVMT) of Nissan Leafs and Chevrolet Volts enrolled in The EV Project.

\section{Which Vehicles Are Being Studied?}

Private owners of Nissan Leafs and Chevrolet Volts in 19 metropolitan areas across the United States participated in The EV Project. They agreed to allow project researchers to electronically monitor the usage of their vehicles throughout the project.

Data collection from Leafs and Volts in The EV Project began in January 2011 and August 2011, respectively. It ended for both groups of vehicles on December 31, 2013. Parameters recorded by the vehicle telematics system included the vehicles' odometer reading. The set of parameters logged by EV Project Volts was expanded on October 1, 2012, to include the EV-mode odometer. This parameter provides the distance driven in EV mode. In order to compare Leaf and Volt eVMT, this study considers data from Leafs and Volts logged from October 1, 2012, through December 31, 2013. Table 1 describes the size of the Leaf and Volt data sets that were analyzed in this study.

Table 1. Description of the EV Project Leaf and Volt data sets.

\begin{tabular}{|l|r|r|}
\hline & Nissan Leaf & Chevrolet Volt \\
\hline Number of vehicles & 4,039 & 1,867 \\
\hline Number of vehicle months & 35,294 & 20,545 \\
\hline Total distance traveled (miles) & $28,520,792$ & $20,950,967$ \\
\hline Distance traveled in EV mode (miles) & $28,520,792$ & $15,599,508$ \\
\hline $\begin{array}{l}\text { Percent of distance traveled in EV } \\
\text { mode }\end{array}$ & $100 \%$ & $74.5 \%$ \\
\hline
\end{tabular}

\section{Discussion of Results}

Monthly eVMT was determined by calculating the change in the Leaf's odometer and the Volt's EV-mode odometer across each vehicle month when sufficient data were reported. Monthly total vehicle miles traveled (VMT) by Volts was also calculated in the same way using the Volt odometer. Volt VMT includes all distances driven, either when in EV mode or in extended-range mode. VMT and eVMT in each vehicle month in the Leaf and Volt data sets were averaged to provide a simple comparison. Table 2 shows these results.

Table 2. Average monthly total and electric vehicle miles traveled.

\begin{tabular}{|l|r|r|}
\hline & Nissan Leaf & Chevrolet Volt \\
\hline Average monthly total VMT & 808.1 & $1,019.8$ \\
\hline Average monthly eVMT & 808.1 & 759.3 \\
\hline
\end{tabular}

The EPA's electric range of the Leaf is approximately double that of the Volt. ${ }^{9}$ However, Leaf drivers in the EV Project averaged only $6 \%$ more actual electric miles per month than Volt drivers. 
To see the variation of VMT and eVMT among vehicles and from month to month, the distributions of these metrics were examined. Figure 1 shows the frequency distributions of the average VMT and eVMT from each vehicle. Each data point in the distributions represents a single vehicle's average over the entire study period. The number of vehicles represented is shown in Table 1.

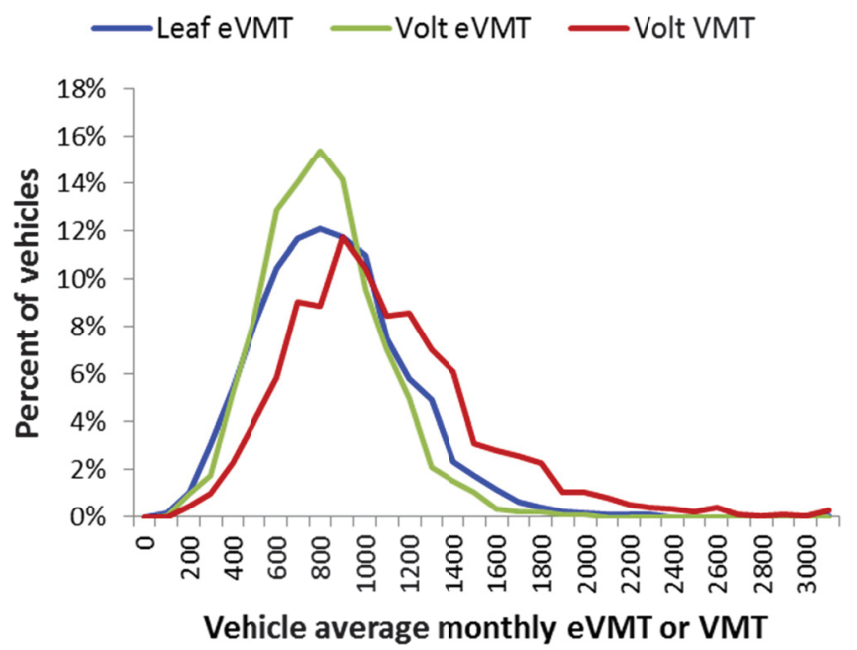

Figure 1. Distribution of vehicle average monthly eVMT and VMT, where each data point in the distributions represents a single vehicle's average over the entire study period.

The range of Volt average monthly VMT extends farther to the right than the range of Leaf eVMT, indicating that some Volt drivers averaged more total miles per month than any Leafs. This is not surprising given that the overall range between refueling of the Chevrolet Volt is five times higher than the Leaf. ${ }^{2}$ However, there is significant overlap between the Volt VMT and Leaf eVMT curves. This means that many Leaf drivers averaged the same or more miles per month than many Volt drivers, despite the Volt's much longer overall range. This illustrates the fact that some drivers have a driving routine that accommodates either vehicle. (Naturally, consumers do not make choices based on their average behavior, but rather their day-to-day driving needs. Such analysis is beyond the scope of this paper, however.)

The distributions of Volt and Leaf average monthly eVMT in Figure 1 are remarkably similar. A large number of Volts averaged the same or higher monthly eVMT than many Leafs, despite having a much shorter electric range. The disparity between electric range and eVMT can be explained by three reasons. First, Volt drivers in The EV Project have been shown to charge more frequently, on average, than Leaf drivers. ${ }^{3}$ Frequent charging extends the effective EV-mode range of the vehicle. Secondly, Volt drivers can fully deplete their batteries and continue to their destinations in extended-range mode, if necessary. Leaf drivers, on the other hand, are less likely to realize their full electric range, because of the impracticality of planning stops for charging precisely when the battery is fully depleted. Finally, Leaf drivers may have purchased their vehicles with the understanding that they do not require long driving range or they have the option of driving a different vehicle on long trips.

Figure 2 shows the frequency distributions of VMT and eVMT per vehicle month. Each data point in these distributions represents a single vehicle month. All vehicle months in the data sets were included. The number of vehicle months represented is shown in Table 1 . The numeric data for the distributions shown in Figures 1 and 2 are included in the tables in the appendix.

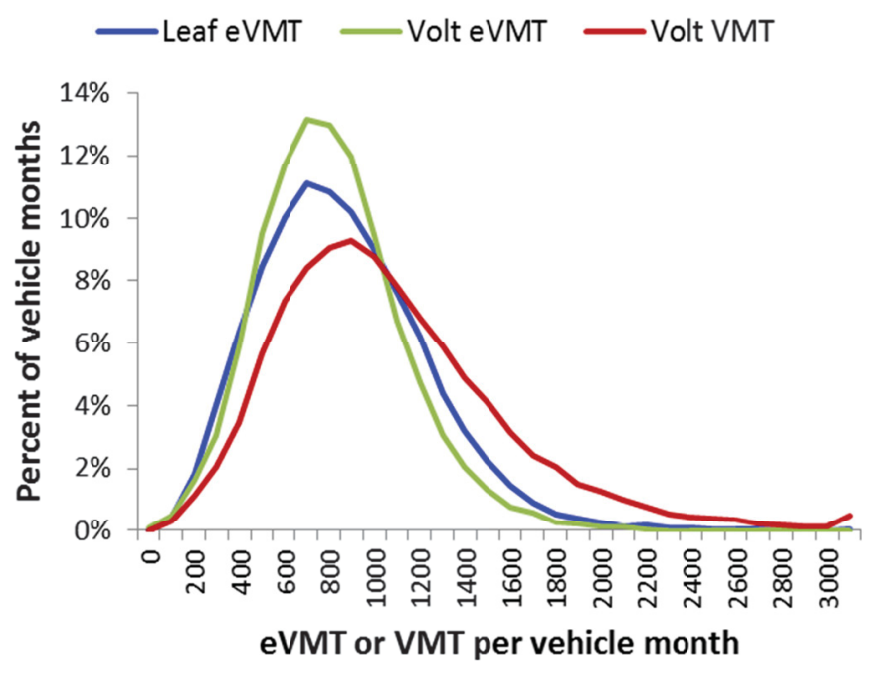

Figure 2. Distribution of eVMT and VMT per vehicle month, where each data point in the distributions represents a single vehicle month.

One would expect the distributions in Figure 2 to be wider than the distributions in Figure 1, because they represent the variation of eVMT and VMT in individual months, rather than variation between one vehicle's average eVMT or VMT to another's vehicle's average. For example, a driver may hypothetically drive 800 miles each month for 14 months and 1,500 miles in 1 month. The single month with an unusually high VMT would not affect the driver's overall average much; therefore, it would not noticeably shift the VMT distribution in Figure 1. However, this single month outlier would be included in the VMT distribution in Figure 2 and it would act to widen the distribution. In light of this, it is significant that the distributions in Figure 2 are only slightly wider than those in Figure 1 . This means that the majority of the variation in eVMT and VMT is between drivers, rather than between months for each driver. 
In addition to calculating the distributions of eVMT and VMT per vehicle month for the entire study period (Figure 2), these distributions were calculated separately for each of the 15 months in the study period. Descriptive statistics describing these monthly distributions were examined to identify changes in behavior over time.

Figure 3 shows lines that connect the median values of the Leaf and Volt eVMT and Volt VMT distributions in each of the 15 months in the study period.

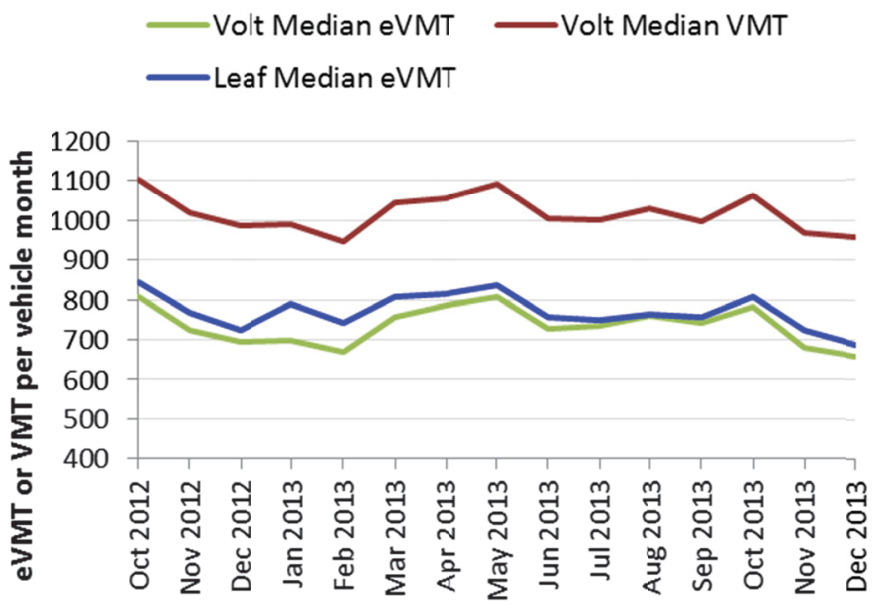

Figure 3. Median eVMT and VMT per vehicle month over time.

The Leaf's median eVMT (blue line) is slightly higher than the Volt's median eVMT (green line) throughout the 15month study period; however, the medians are nearly equal in August 2013. The eVMT medians rise and fall fairly proportionally, with only a few exceptions. The $25^{\text {th }}$ and $75^{\text {th }}$ percentile values for the distributions each month (not shown) rise and fall with the medians, indicating that the shapes of the distributions are relatively constant month after month. This proportional shifting of the distributions overtime suggests that seasonal effects influence both Leaf and Volt drivers in the same way. Regional analysis is needed to confirm this hypothesis.

The ratio of the Volt's median eVMT to its median VMT (red line) is the percentage of distance traveled in EV mode each month. Visual inspection of Figure 3 shows this value remained relatively consistent. There was seasonal variation, however; the months of April through October saw $74 \%$ to $77 \%$ of distance in $\mathrm{EV}$ mode, whereas vehicles averaged $70 \%$ to $74 \%$ miles in EV mode in November through March. This metric by month is included in the Table A3 in the appendix, along with descriptive statistics for the monthly eVMT and VMT distributions.

\section{About The EV Project}

The EV Project was the largest plug-in electric vehicle infrastructure demonstration project in the world, equally funded by the U.S. Department of Energy (DOE) through the American Recovery and Reinvestment Act and private sector partners. The EV Project deployed over 12,000 AC Level 2 charging stations for residential and commercial use, as well as over 100 dual-port DC fast chargers. Approximately 8,300 Nissan LEAFs ${ }^{\mathrm{TM}}$, Chevrolet Volts, and Smart ForTwo Electric Drive vehicles were enrolled in the project.

Project participants gave written consent for EV Project researchers to collect and analyze data from their vehicles and/or charging units. Data collected from the vehicles and charging infrastructure represented almost 125 million miles of driving and 4 million charging events. The data collection phase of The EV Project ran from January 1, 2011, through December 31, 2013. Idaho National Laboratory is responsible for analyzing the data and publishing summary reports, technical papers, and lessons learned on vehicle and charging unit use. This material is based on work supported by DOE under Award Number DE-EE-0002194.

\section{Company Profile}

Idaho National Laboratory is one of DOE's 10 multiprogram national laboratories. The laboratory performs work in each of DOE's strategic goal areas: energy, national security, science, and the environment. Idaho National Laboratory is the nation's leading center for nuclear energy research and development. Day-to-day management and operation of the laboratory is the responsibility of Battelle Energy Alliance.

For more information, visit avt.inl.gov/evproject.shtml.

\section{References}

1. www.fueleconomy.gov gives an EPA-estimated electric range of 73 miles for MY2011/2012 Nissan Leafs and 75 miles for the MY2013 Leaf; the EPA electric range is 35 miles for MY2011/2012 Volts and 38 miles for MY2013 Volts. Leafs and Volts enrolled in The EV Project include a mix of these model years.

2. www.fueleconomy.gov gives an EPA-estimated overall range of 380 miles for the MY2011-2013 Chevrolet Volt.

3. The report "Observations from The EV Project in Q4 2013" explains that EV Project Leafs have consistently averaged 1.1 charging events per day driven and Volt have averaged between 1.4 and 1.5 charging events per vehicle day driven since the beginning of the project. See http://avt.inl.gov/pdf/EVProj/EVProjectSummaryReport Q42013FINAL.pdf About The EV Project 


\section{EVProject}

\section{Appendices}

Table A1. Values used to create the frequency distributions shown in Figure 1.

\begin{tabular}{|c|c|c|c|}
\hline $\begin{array}{l}\text { Distance Bin } \\
\text { (miles) }\end{array}$ & $\begin{array}{l}\text { Leaf } \\
\text { Frequency }\end{array}$ & $\begin{array}{l}\text { Volt } \\
\text { Frequency } \\
\text { (Total } \\
\text { Miles) }\end{array}$ & $\begin{array}{l}\text { Volt } \\
\text { Frequency } \\
\text { (EV-mode } \\
\text { Miles) }\end{array}$ \\
\hline 0 & 0 & 0 & 0 \\
\hline$>0-100$ & 7 & 0 & 1 \\
\hline$>100-200$ & 43 & 8 & 18 \\
\hline$>200-300$ & 122 & 18 & 33 \\
\hline$>300-400$ & 219 & 42 & 98 \\
\hline$>400-500$ & 328 & 76 & 157 \\
\hline$>500-600$ & 423 & 110 & 240 \\
\hline$>600-700$ & 472 & 169 & 262 \\
\hline$>700-800$ & 488 & 166 & 287 \\
\hline$>800-900$ & 475 & 219 & 264 \\
\hline$>900-1000$ & 444 & 195 & 179 \\
\hline$>1000-1100$ & 304 & 158 & 131 \\
\hline$>1100-1200$ & 234 & 160 & 93 \\
\hline$>1200-1300$ & 200 & 132 & 39 \\
\hline$>1300-1400$ & 94 & 114 & 28 \\
\hline$>1400-1500$ & 70 & 58 & 19 \\
\hline$>1500-1600$ & 46 & 52 & 6 \\
\hline$>1600-1700$ & 26 & 48 & 4 \\
\hline$>1700-1800$ & 15 & 43 & 4 \\
\hline$>1800-1900$ & 10 & 20 & 2 \\
\hline$>1900-2000$ & 7 & 19 & 2 \\
\hline$>2000-2100$ & 3 & 15 & 0 \\
\hline$>2100-2200$ & 3 & 10 & 0 \\
\hline$>2200-2300$ & 4 & 7 & 0 \\
\hline$>2300-2400$ & 0 & 6 & 0 \\
\hline$>2400-2500$ & 0 & 4 & 0 \\
\hline$>2500-2600$ & 0 & 7 & 0 \\
\hline$>2600-2700$ & 0 & 2 & 0 \\
\hline$>2700-2800$ & 0 & 1 & 0 \\
\hline$>2800-2900$ & 0 & 2 & 0 \\
\hline$>2900-3000$ & 1 & 1 & 0 \\
\hline \multirow[t]{2}{*}{$>3000$} & 1 & 5 & 0 \\
\hline & 4039 & 1867 & 1867 \\
\hline
\end{tabular}

Table A2. Values used to create the frequency distributions shown in Figure 2.

\begin{tabular}{|c|c|c|c|}
\hline $\begin{array}{l}\text { Distance Bin } \\
\text { (miles) }\end{array}$ & $\begin{array}{l}\text { Leaf } \\
\text { Frequency }\end{array}$ & $\begin{array}{l}\text { Volt } \\
\text { Frequency } \\
\text { (Total } \\
\text { Miles) }\end{array}$ & $\begin{array}{l}\text { Volt } \\
\text { Frequency } \\
\text { (EV-mode } \\
\text { Miles) }\end{array}$ \\
\hline 0 & 0 & 0 & 16 \\
\hline$>0-100$ & 158 & 62 & 97 \\
\hline$>100-200$ & 648 & 233 & 339 \\
\hline$>200-300$ & 1410 & 416 & 629 \\
\hline$>300-400$ & 2235 & 716 & 1214 \\
\hline$>400-500$ & 2987 & 1161 & 1952 \\
\hline$>500-600$ & 3540 & 1511 & 2409 \\
\hline$>600-700$ & 3921 & 1725 & 2703 \\
\hline$>700-800$ & 3818 & 1860 & 2671 \\
\hline$>800-900$ & 3592 & 1905 & 2465 \\
\hline$>900-1000$ & 3173 & 1800 & 1942 \\
\hline$>1000-1100$ & 2701 & 1604 & 1377 \\
\hline$>1100-1200$ & 2200 & 1400 & 971 \\
\hline$>1200-1300$ & 1546 & 1209 & 632 \\
\hline$>1300-1400$ & 1131 & 1006 & 420 \\
\hline$>1400-1500$ & 783 & 842 & 267 \\
\hline$>1500-1600$ & 511 & 649 & 161 \\
\hline$>1600-1700$ & 319 & 498 & 119 \\
\hline$>1700-1800$ & 194 & 419 & 56 \\
\hline$>1800-1900$ & 145 & 312 & 41 \\
\hline$>1900-2000$ & 94 & 261 & 28 \\
\hline$>2000-2100$ & 48 & 205 & 21 \\
\hline$>2100-2200$ & 55 & 155 & 9 \\
\hline$>2200-2300$ & 24 & 111 & 2 \\
\hline$>2300-2400$ & 20 & 93 & 1 \\
\hline$>2400-2500$ & 10 & 82 & 0 \\
\hline$>2500-2600$ & 9 & 72 & 0 \\
\hline$>2600-2700$ & 4 & 43 & 1 \\
\hline$>2700-2800$ & 1 & 38 & 1 \\
\hline$>2800-2900$ & 0 & 29 & 1 \\
\hline$>2900-3000$ & 2 & 29 & 0 \\
\hline \multirow[t]{2}{*}{$>3000$} & 15 & 99 & 0 \\
\hline & 3529 & 20545 & 20545 \\
\hline
\end{tabular}


Table A3. eVMT/VMT descriptive statistics by month and overall for the distributions whose median values are depicted in Figure 3.

\begin{tabular}{|c|c|c|c|c|c|c|c|c|c|c|c|c|c|}
\hline & Month & $\begin{array}{c}\text { Number } \\
\text { of } \\
\text { vehicle } \\
\text { months }\end{array}$ & Total miles & $\begin{array}{l}\text { Percent of miles } \\
\text { in EV mode }\end{array}$ & avg & $\begin{array}{l}\text { std } \\
\text { dev }\end{array}$ & $\max$ & 95th & 75th & median & 25th & 5 th & $\min$ \\
\hline \multirow[t]{16}{*}{ Leaf } & Oct 2012 & 2304 & 2043334 & -- & 886.9 & 399.8 & 3460.1 & 1571.5 & 1127.3 & 845.5 & 600.1 & 303.8 & 41.4 \\
\hline & Nov 2012 & 2376 & 1895713 & -- & 797.9 & 361.8 & 3236.9 & 1408.5 & 1013.6 & 767.9 & 542.1 & 278.1 & 68.2 \\
\hline & Dec 2012 & 2683 & 2032197 & -- & 757.4 & 334.2 & 2221.2 & 1351.3 & 961.1 & 724.8 & 510.9 & 275.0 & 41.0 \\
\hline & Jan 2013 & 2807 & 2287247 & -- & 814.8 & 367.9 & 3448.7 & 1441.9 & 1049.1 & 788.8 & 545.1 & 277.9 & 32.7 \\
\hline & Feb 2013 & 2709 & 2094318 & -- & 773.1 & 352.0 & 3139.4 & 1378.6 & 990.0 & 742.7 & 523.1 & 252.9 & 36.1 \\
\hline & Mar 2013 & 2518 & 2113081 & -- & 839.2 & 375.7 & 3242.5 & 1497.3 & 1068.5 & 807.7 & 567.6 & 290.8 & 25.9 \\
\hline & Apr 2013 & 2511 & 2141590 & -- & 852.9 & 394.8 & 3658.2 & 1531.9 & 1092.6 & 815.9 & 564.6 & 273.3 & 55.1 \\
\hline & May 2013 & 2506 & 2168769 & -- & 865.4 & 389.5 & 3485.6 & 1542.6 & 1100.5 & 836.4 & 583.2 & 292.1 & 35.5 \\
\hline & Jun 2013 & 2472 & 1954500 & -- & 790.7 & 362.3 & 3616.4 & 1439.9 & 1007.1 & 755.0 & 529.8 & 264.1 & 27.8 \\
\hline & Jul 2013 & 2474 & 1940921 & -- & 784.5 & 373.8 & 4050.0 & 1432.5 & 1001.8 & 748.3 & 518.7 & 251.9 & 59.8 \\
\hline & Aug 2013 & 2406 & 1941879 & -- & 807.1 & 374.0 & 3822.2 & 1474.8 & 1038.6 & 764.7 & 542.4 & 276.3 & 49.8 \\
\hline & Sep 2013 & 2255 & 1776002 & -- & 787.6 & 358.9 & 2578.8 & 1419.9 & 1019.8 & 756.9 & 524.4 & 255.4 & 36.4 \\
\hline & Oct 2013 & 2268 & 1904190 & -- & 839.6 & 385.4 & 3630.1 & 1497.9 & 1092.7 & 806.0 & 560.2 & 267.4 & 23.1 \\
\hline & Nov 2013 & 1891 & 1425968 & -- & 754.1 & 334.4 & 3074.3 & 1320.2 & 956.8 & 724.1 & 501.0 & 284.5 & 42.0 \\
\hline & Dec 2013 & 1114 & 801080 & -- & 719.1 & 318.8 & 2311.9 & 1305.7 & 913.3 & 686.9 & 492.7 & 259.5 & 67.8 \\
\hline & Overall & 35294 & 28520792 & -- & 808.1 & 370.3 & 4050.0 & 1457.5 & 1033.2 & 772.0 & 541.5 & 273.1 & 23.1 \\
\hline \multirow[t]{16}{*}{ Volt EV mi } & Oct 2012 & 976 & 802293 & 0.744 & 822.0 & 326.1 & 2023.4 & 1417.5 & 1008.6 & 808.1 & 590.6 & 346.3 & 70.8 \\
\hline & Nov 2012 & 981 & 722734 & 0.724 & 736.7 & 294.2 & 1778.5 & 1273.8 & 909.9 & 723.6 & 530.4 & 302.2 & 0.0 \\
\hline & Dec 2012 & 1014 & 717850 & 0.718 & 707.9 & 278.8 & 1819.2 & 1184.9 & 877.9 & 696.1 & 518.8 & 280.1 & 0.0 \\
\hline & Jan 2013 & 1037 & 749123 & 0.730 & 722.4 & 291.3 & 2105.5 & 1248.8 & 891.0 & 699.3 & 518.8 & 305.2 & 6.3 \\
\hline & Feb 2013 & 1119 & 771020 & 0.729 & 689.0 & 282.0 & 1831.5 & 1210.9 & 850.6 & 668.8 & 497.0 & 251.0 & 21.6 \\
\hline & Mar 2013 & 1608 & 1243684 & 0.739 & 773.4 & 311.0 & 2270.8 & 1328.4 & 949.6 & 755.5 & 553.8 & 315.6 & 33.8 \\
\hline & Apr 2013 & 1655 & 1332180 & 0.762 & 804.9 & 324.2 & 2115.9 & 1375.6 & 990.7 & 784.3 & 575.5 & 328.0 & 16.7 \\
\hline & May 2013 & 1647 & 1369228 & 0.761 & 831.3 & 338.7 & 2035.3 & 1424.1 & 1048.7 & 805.8 & 594.4 & 322.1 & 0.0 \\
\hline & Jun 2013 & 1551 & 1181475 & 0.757 & 761.8 & 304.6 & 2141.2 & 1294.1 & 947.8 & 727.3 & 544.4 & 309.1 & 39.9 \\
\hline & Jul 2013 & 1548 & 1173096 & 0.757 & 757.8 & 324.4 & 2111.7 & 1324.0 & 946.8 & 735.2 & 538.6 & 265.3 & 0.0 \\
\hline & Aug 2013 & 1560 & 1208159 & 0.752 & 774.5 & 336.9 & 2816.7 & 1345.7 & 971.8 & 759.5 & 529.9 & 282.6 & 0.0 \\
\hline & Sep 2013 & 1588 & 1214348 & 0.766 & 764.7 & 326.6 & 2760.4 & 1324.5 & 956.3 & 741.2 & 538.1 & 296.3 & 0.0 \\
\hline & Oct 2013 & 1575 & 1264589 & 0.756 & 802.9 & 336.6 & 2628.8 & 1379.9 & 998.0 & 783.5 & 572.3 & 303.0 & 0.0 \\
\hline & Nov 2013 & 1556 & 1089834 & 0.724 & 700.4 & 290.8 & 1910.8 & 1224.0 & 871.9 & 679.6 & 505.9 & 256.5 & 0.0 \\
\hline & Dec 2013 & 1130 & 759894 & 0.703 & 672.5 & 269.4 & 1966.1 & 1133.2 & 831.0 & 659.4 & 482.5 & 256.6 & 0.0 \\
\hline & Overall & 20545 & 15599508 & 0.745 & 759.3 & 316.0 & 2816.7 & 1319.4 & 942.1 & 733.9 & 537.7 & 294.1 & 0.0 \\
\hline \multirow[t]{16}{*}{ Volt total mi } & Oct 2012 & 976 & 1077949 & -- & 1104.5 & 561.3 & 5501.2 & 2144.2 & 1376.9 & 1008.2 & 707.1 & 402.8 & 70.8 \\
\hline & Nov 2012 & 981 & 998797 & -- & 1018.1 & 510.7 & 3450.3 & 1973.5 & 1269.5 & 932.5 & 650.6 & 375.8 & 66.5 \\
\hline & Dec 2012 & 1014 & 1000147 & -- & 986.3 & 494.8 & 4507.2 & 1865.1 & 1247.8 & 908.9 & 648.1 & 351.2 & 47.0 \\
\hline & Jan 2013 & 1037 & 1025511 & -- & 988.9 & 489.9 & 3132.7 & 1908.8 & 1213.9 & 914.2 & 650.0 & 366.4 & 44.2 \\
\hline & Feb 2013 & 1119 & 1056934 & -- & 944.5 & 503.1 & 4070.0 & 1873.2 & 1177.7 & 858.8 & 606.1 & 296.1 & 21.6 \\
\hline & Mar 2013 & 1608 & 1682036 & -- & 1046.0 & 521.8 & 5153.7 & 1966.0 & 1300.1 & 960.9 & 690.1 & 374.9 & 33.8 \\
\hline & Apr 2013 & 1655 & 1748657 & -- & 1056.6 & 516.5 & 3778.9 & 2022.1 & 1330.2 & 961.9 & 700.5 & 392.8 & 16.7 \\
\hline & May 2013 & 1647 & 1799082 & -- & 1092.3 & 530.7 & 4808.6 & 2058.3 & 1392.8 & 1019.2 & 710.2 & 384.0 & 70.9 \\
\hline & Jun 2013 & 1551 & 1560323 & -- & 1006.0 & 503.8 & 4499.0 & 1945.8 & 1267.6 & 918.6 & 652.7 & 348.6 & 42.6 \\
\hline & Jul 2013 & 1548 & 1549903 & -- & 1001.2 & 522.7 & 4993.1 & 1965.4 & 1246.7 & 928.2 & 651.2 & 321.5 & 93.7 \\
\hline & Aug 2013 & 1560 & 1606429 & -- & 1029.8 & 541.1 & 4581.9 & 1985.2 & 1295.4 & 935.1 & 652.7 & 326.4 & 84.8 \\
\hline & Sep 2013 & 1588 & 1585188 & -- & 998.2 & 493.7 & 3811.6 & 1922.9 & 1277.2 & 925.2 & 652.6 & 347.6 & 57.0 \\
\hline & Oct 2013 & 1575 & 1672355 & -- & 1061.8 & 529.3 & 4180.7 & 2061.2 & 1334.8 & 979.1 & 708.1 & 350.2 & 34.1 \\
\hline & Nov 2013 & 1556 & 1505982 & -- & 967.9 & 495.2 & 4162.9 & 1876.0 & 1228.8 & 875.8 & 636.5 & 328.4 & 49.0 \\
\hline & Dec 2013 & 1130 & 1081674 & -- & 957.2 & 480.1 & 3651.3 & 1852.9 & 1212.0 & 877.2 & 617.4 & 339.3 & 29.1 \\
\hline & Overall & 20545 & 20950967 & -- & 1019.8 & 516.1 & 5501.2 & 1969.1 & 1283.0 & 935.5 & 660.7 & 350.1 & 16.7 \\
\hline
\end{tabular}

